\title{
Retinal Cavernous Hemangioma
}

National Cancer Institute

\section{Source}

National Cancer Institute. Retinal Cavernous Hemangioma. NCI Thesaurus. Code C4921.

A cavernous hemangioma arising from the retina. 